\title{
14-3-3 zeta is a molecular target in guggulsterone induced apoptosis in Head and Neck cancer cells
}

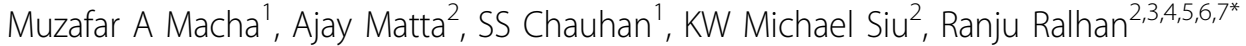

\begin{abstract}
Background: The five-year survival rates for head and neck squamous cell carcinoma (HNSCC) patients are less than 50\%, and the prognosis has not improved, despite advancements in standard multi-modality therapies. Hence major emphasis is being laid on identification of novel molecular targets and development of multi-targeted therapies. 14-3-3 zeta, a multifunctional phospho-serine/phospho-threonine binding protein, is emerging as an effector of pro-survival signaling by binding to several proteins involved in apoptosis (Bad, FKHRL1 and ASK1) and may serve as an appropriate target for head and neck cancer therapy. Herein, we determined effect of guggulsterone (GS), a farnesoid X receptor antagonist, on 14-3-3 zeta associated molecular pathways for abrogation of apoptosis in head and neck cancer cells.

Methods: Head and neck cancer cells were treated with guggulsterone (GS). Effect of GS-treatment was evaluated using cell viability (MTT) assay and apoptosis was verified by annexin V, DNA fragmentation and M30 CytoDeath antibody assay. Mechanism of GS-induced apoptosis was determined by western blotting and co-IP assays using specific antibodies.

Results: Using in vitro models of head and neck cancer, we showed 14-3-3 zeta as a key player regulating apoptosis in GS treated SCC4 cells. Treatment with GS releases BAD from the inhibitory action of 14-3-3 zeta in proliferating HNSCC cells by activating protein phosphatase 2A (PP2A). These events initiate the intrinsic mitochondrial pathway of apoptosis, as revealed by increased levels of cytochrome $\mathrm{c}$ in cytoplasmic extracts of GStreated SCC4 cells. In addition, GS treatment significantly reduced the expression of anti-apoptotic proteins, BCl-2, xIAP, Mcl1, survivin, cyclin D1 and c-myc, thus committing cells to apoptosis. These events were followed by activation of caspase 9, caspase 8 and caspase 3 leading to cleavage of its downstream target, poly-ADP-ribose phosphate (PARP).
\end{abstract}

Conclusion: GS targets 14-3-3 zeta associated cellular pathways for reducing proliferation and inducing apoptosis in head and neck cancer cells, warranting its investigation for use in treatment of head and neck cancer.

\section{Background}

Head and neck squamous cell carcinoma (HNSCC) is the sixth most common cancer in the U.S. and the fourth most prevalent cancer in men worldwide, accounting for over 500,000 new cases annually [1]. The 5 -year survival rate is less than $50 \%$, and the prognosis of advanced cases has not improved much over the past three decades [2,3]. Despite standard multi-modality therapeutic interventions, including surgery, radiation and/or chemo-radiotherapy, head and neck cancer

\footnotetext{
* Correspondence: rralhan@mtsinai.on.ca

${ }^{2}$ Department of Chemistry and Centre for Research In Mass Spectrometry,

York University, 4700 Keele Street, Toronto, Ontario, Canada M3J 1P3

Full list of author information is available at the end of the article
}

patients have a substantial risk of developing second primary tumors, often attributed to "field cancerization" molecular alterations arising due to chronic carcinogen exposure of the upper aerodigestive tract [4-6]. Moreover, the limited efficacy, lack of safety, and high cost of mono-targeted therapies including EGFR inhibitors, limit their use in head and neck cancer management [7-9]. Hence major emphasis is being laid on identification of novel molecular targets and development of multi-targeted therapies. Clinical development of agents that can delay onset and/or progression could significantly improve the management of head and neck cancer. 
Guggulsterone (GS), [4, 17(20)-pregnadiene-3, 16-dione], obtained from the plant Commiphora mukkul is used for treatment of obesity, hyperlipidemia, atherosclerosis, diabetes and osteoarthritis [10-12]. Besides, GS has also been reported to induce apoptosis, suppress proliferation, invasion, angiogenesis and metastasis in a wide variety of human cancer cell lines, including acute myeloid leukemia, head and neck, prostate, lung, breast, colon and ovarian cancer [13-22]. Interestingly, normal human fibroblasts, non-transformed prostate and colon epithelial cell lines are relatively resistant to growth inhibition by GS in comparison to cancer cells $[13,16,18]$. Various mechanisms have been proposed to explain the anti-carcinogenic effects of GS, including inhibition of reactive oxygen species (ROS), suppression of inflammation and inhibition of nuclear receptors (farnesoid $\mathrm{X}$ receptors), transcription factors [nuclear factor kappa B $(\mathrm{NF} \kappa \mathrm{B})$, signal transducer and activator of transcription 3 (STAT3)], anti-apoptotic (Bcl-2, Bax, Bad and xIAP) and cell cycle-regulatory proteins (p21, p16 and cyclin D1). In addition, Leeman-Neill et al., [23] recently showed GS-treatment decreased the expression of both pSTAT3 (p-tyr-705), total STAT3 and hypoxia-inducible factor (HIF)-1 $\alpha$ in HNSCC cell lines and in a xenograft model of HNSCC. Similarly, in our earlier reports, we also demonstrated GS reduced the levels of pSTAT3 (p-tyr-705) in both multiple myeloma and HNSCC cell lines [24].

14-3-3 family of proteins consists of seven members $(\zeta, \sigma, \beta, \eta, \theta, \gamma$ and $\varepsilon$ ) which are multifunctional phospho-serine/phospho-threonine binding molecules that can serve as effectors of survival signaling [25]. Recently, using quantitative proteomics screens we identified a panel of proteins including 14-3-3 zeta, as biomarkers for diagnosis and prognosis of head and neck cancer with a high sensitivity and specificity [25-29] and suggested their involvement in development and progression of head and neck cancer. An emerging role for 14-3-3 zeta as an effectors of prosurvival signaling is suggested in part by the large number of 14-3-3 binding proteins involved in apoptosis, such as A20, ASK1, FKHRL1 and Bad [25,30-35]. In addition, using in vitro models of head and neck cancer, we also showed knocking down expression of 14-3-3 zeta sensitizes head and neck cancer cells to chemotherapy [36], revealing its therapeutic potential.

In the current study, we investigated the effect of GS on 14-3-3 zeta and its role in GS-induced apoptosis in HNSCC cells. Our results demonstrated GS-induces apoptosis by intrinsic mitochondrial pathway by a protein phosphatase mediated dephosphorylation of Bad, thus releasing it from inhibitory action of 14-3-3 zeta, which sequesters it in cytoplasm of proliferating cells.

\section{Methods}

\section{Antibodies and Reagents}

Z-guggulsterone (GS), 3-(4, 5-dimethylthiazol-2-yl)-2, 5 -diphenyltetrazolium bromide (MTT), propidium iodide (PI) were purchased from Sigma (St. Louis, MO). For details of the antibodies used in this study, see Additional file 1: Supplementary Table S1. Caspase-3 activity assay kit was obtained from R\&D systems (Minneapolis, MN); Caspase- 9 and Caspase- 8 activity assay kit from Genentech (South San Francisco, CA). Protein A-sepharose beads were obtained from GE Healthcare Biosciences, (Uppsala, Sweden).

\section{Cell culture}

Human head and neck squamous carcinoma cell lines, SCC4 was obtained from American Type Culture Collection (ATCC) and HSC2 (JCRB0622) was obtained from Health Science Research Resources Bank (HSRRB), Japan, were grown in monolayer cultures in Dulbecco's modified eagle medium (DMEM) (Sigma, St. Louis, MO) supplemented with $10 \%$ fetal bovine serum (FBS) (Sigma), $1 \mathrm{mM}$ L-glutamine, $1 \mathrm{mM}$ minimum essential medium (MEM), $100 \mu \mathrm{g} / \mathrm{ml}$ streptomycin and $100 \mathrm{U} / \mathrm{ml}$ penicillin in a humidified incubator (5\% carbon-dioxide, $95 \%$ air) at $37^{\circ} \mathrm{C}$ as described earlier [36]. For the assays described below, unless specified, head and neck cancer cells were cultured in $100 \mathrm{~mm}$ culture dishes for $24 \mathrm{~h}$, followed by treatment with GS $(50 \mu \mathrm{M})$ in DMEM only (without FBS) or medium containing DMSO $(<0.05 \%)$ which served as a vehicle control.

\section{Cell viability assay}

Head and neck cancer cells $\left(5 \times 10^{3} /\right.$ well $)$ were plated in a 96-well plate for $24 \mathrm{hrs}$. Cells were incubated in triplicates in the presence of medium containing GS (0 - 100 $\mu \mathrm{M})$ or $0.02 \%$ of DMSO which served as a vehicle control in a final volume of $100 \mu \mathrm{l}$ for $24-72 \mathrm{hrs}$ at $37^{\circ} \mathrm{C}$. Cell death was measured by adding 3-(4,5-dimethylthiazol-2-yl)-2,5-diphenyltetrazolium bromide (MTT) at $37^{\circ}$ $\mathrm{C}$ for 3-4 h. The formazan crystals were dissolved in $100 \mu \mathrm{l}$ of dimethylsulphoxide (DMSO) and optical density (OD) was measured at wavelength of $570 \mathrm{~nm}$. The percentage cell death was calculated individually for each dose as follows: $\left(\mathrm{OD}_{\text {control }}-\mathrm{OD}_{\text {treated }} / \mathrm{OD}_{\text {control }}\right) \times$ 100 . The percentage cell viability was calculated as [\% of viable cells $=(100-\%$ cell death $)][36]$.

\section{Cell cycle analysis using flow cytometry}

GS-treated and untreated, control SCC4 cells collected at $24 \mathrm{~h}$ and $48 \mathrm{~h}$ were washed with phosphate buffer saline (PBS, $\mathrm{pH}=7.4$ ). The cells were fixed in $70 \%$ ethanol for $30 \mathrm{~min}$ at $-20^{\circ} \mathrm{C}$ and resuspended in buffer containing PBS-EDTA $(0.5 \mathrm{M}, \mathrm{pH}=8.0)$, Triton $\mathrm{X}-100$ 
(0.05\%), RNAse A (50 $\mu \mathrm{g} / \mathrm{ml})$ and propidium iodide (PI, $100 \mu \mathrm{g} / \mathrm{ml}$ ) for flow cytometry analysis. The PI-labeled cells were analyzed using a BD Canto flow cytometer and the output thus obtained was analyzed using the BD FACS Diva software (BD Biosciences, CA) [36].

\section{Annexin $\mathrm{V}$ assay}

Annexin $\mathrm{V}$ and propidium iodide double staining was used to quantify apoptosis. Control and GS-treated SCC4 cells were harvested at $24 \mathrm{~h}$ and $48 \mathrm{~h}$, washed with ice-cold PBS ( $\mathrm{pH}=7.4)$, resuspended in cold calcium binding medium (10 mM HEPES, pH 7.4, 140 $\mathrm{mM} \mathrm{NaCl}$ and $2.5 \mathrm{mM} \mathrm{CaCl}_{2}$ ), and stained with FITClabeled annexin $\mathrm{V}$ and propidium iodide, following manufacturer's protocol (R\&D Systems, Minneapolis, MN). Following incubation at room temperature for $15 \mathrm{~min}$ in the dark, cells were analyzed with FACS CantoTM flow cytometer (BD Biosciences, San Jose, CA) [36].

\section{DNA fragmentation assay}

SCC4 cells $\left(2 \times 10^{6}\right)$ were treated with GS for different time intervals; harvested, resuspended in $200 \mu \mathrm{l}$ of ice cold lysis buffer containing $10 \mathrm{mM}$ Tris- $\mathrm{HCl}(\mathrm{pH}=7.4)$, $150 \mathrm{mM} \mathrm{NaCl}, 5 \mathrm{mM}$ EDTA and $0.5 \%$ Triton X-100 and incubated for $30 \mathrm{~min}$. Lysates were vortexed and cleared by centrifugation at 10,000 g for $20 \mathrm{~min}$. Fragmented DNA in the supernatant was extracted with an equal volume of neutral phenol: choloroform: isoamyl alcohol (25:24:1, vol/vol/vol) and analyzed electrophoretically on $1.5 \%$ agarose gel containing ethidium bromide after measuring the DNA content using UVspectrophotometer.

\section{M30 CytoDeath Antibody Assay}

The M30 CytoDeath antibody binds to a caspase-cleaved formalin resistant epitope of cytokeratin 18, which is exposed during early apoptosis. Expression and localization of M30 protein was observed in GS treated and untreated control SCC4 cells using confocal laser scan microscopy as described by earlier [37]. Briefly, GS treated and control SCC4 cells grown over coverslip, were fixed in methanol for $20 \mathrm{~min}$ at $-20^{\circ} \mathrm{C}$, rinsed with PBS $(\mathrm{pH}=7.2)$ and incubated with M30 CytoDeath antibody overnight at $4^{\circ} \mathrm{C}$. After rinsing in PBS, the coverslips were incubated with biotinylated secondary antibody (LSAB plus Kit, DAKO Cytomations, Denmark) for $45 \mathrm{~min}$ at $37^{\circ} \mathrm{C}$ followed by incubation with streptavidin-conjugated fluorochrome, fluorescein isothiocyanate (FITC) (DAKO Cytomations, Glostrup, Denmark). Thereafter, the coverslips were counterstained with propidium iodide (PI, 10 $\mathrm{mg} / \mathrm{ml}$; Sigma, MO) for $30 \mathrm{sec}$. Coverslips were rinsed, mounted with antifade agent and examined using a confocal laser scanning microscope (CLSM)-LSM510 scanning module (Carl Zeiss Microscopy, Jena GmbH, Germany).

\section{Co-immunoprecipitation (co-IP) assays}

Co-immunoprecipitation (co-IP) assays were carried out using specific antibodies and analyzed by western blotting. Briefly, head and neck cancer cells (SCC4) were rinsed in ice-cold PBS and lysed in IP lysis buffer [37]. Lysates were incubated on ice for $30 \mathrm{~min}$. and cell debris was removed by centrifugation. Lysates were precleared by adding $20 \mu \mathrm{l}$ of Protein A Sepharose (GE Healthcare Biosciences, Uppsala, Sweden), followed by overnight incubation with specific antibodies (polyclonal anti-14-3-3zeta/anti-Bax or monoclonal anti-Bad/anti$\mathrm{Bcl} 2 /$ anti-Bcl-xL antibody) on a rocker at $4^{\circ} \mathrm{C}$. Immunocomplexes were pulled down by incubating with Protein A-Sepharose for $2 \mathrm{~h}$ at $4^{\circ} \mathrm{C}$, followed by washing with $4 \mathrm{X}$ ice-cold lysis buffer to eliminate non-specific interactions [37]. Protein A-sepharose-bound immunocomplexes were then resuspended in Laemelli sample buffer, boiled for $5 \mathrm{~min}$. and analyzed by Western blotting using specific antibodies as described below.

\section{Western blotting (WB)}

Whole-cell lysates were prepared from GS-treated SCC4 cells and protein concentration was determined using the Bradford reagent (Sigma) and equal amounts of proteins $(60 \mu \mathrm{g} /$ lane) were resolved on $12 \%$ sodium dodecyl sulfate (SDS)-polyacrylamide gel [37]. The proteins were then electro-transferred onto polyvinylidene fluoride (PVDF) membrane. After blocking with 5\% non-fat milk in Tris-buffered saline (TBS, $0.1 \mathrm{M}, \mathrm{pH}=7.4$ ), blots were incubated with specific antibodies as per manufacturer's recommended protocol at $4^{\circ} \mathrm{C}$ overnight. Protein abundance of $\alpha$-tubulin (Santa Cruz Biotechnology, CA) served as a control for protein loading in each lane. Membranes were incubated with HRP-conjugated secondary antibodies, (DAKO Cytomation, Glostrup, Denmark), diluted at an appropriate dilution in 1\% BSA, for $2 \mathrm{~h}$ at room temperature. After each step, blots were washed three times with Tween $(0.1 \%)$-Tris-buffer saline (TTBS). Protein bands were detected by the enhanced chemiluminescence method (ECL), Santa Cruz Biotechnology (Santa Cruz, CA) on XO-MAT film.

\section{Cytochrome c release Assay}

SCC4 cells $\left(2 \times 10^{5} /\right.$ well $)$ were cultured in 6 -well plates for $24 \mathrm{~h}$ followed by treatment with GS washed with ice - cold PBS ( $\mathrm{pH}=7.2)$ and resuspended in isotonic mitochondrial buffer (210 mM mannitol, $70 \mathrm{mM}$ sucrose, 1 mM EGTA, 10 mM Hepes, pH 7.5, 0.1\% BSA) containing protease inhibitor cocktail. The resuspended cells were homogenized with a polytron homogenizer and then centrifuged at $2000 \mathrm{~g}$ for $3 \mathrm{~min}$ to pellet the nuclei and unbroken cells. The supernatant was centrifuged at $13,000 \mathrm{~g}$ for $10 \mathrm{~min}$ to pellet mitochondria [38]. The supernatant was further centrifuged at $15,000 \mathrm{~g}$ to pellet 
light membranes. The resulting supernatant contained the cytosolic fractions. The mitochondrial fraction was washed with mitochondrial buffer twice, resuspended with $1 \%$ Non-Idet P-40 lysis buffer, mixed for $60 \mathrm{~min}$, and then centrifuged at $13,000 \mathrm{~g}$ for $10 \mathrm{~min}$ at $4^{\circ} \mathrm{C}$. The supernatant containing mitochondrial proteins was collected and each sub-cellular fraction was subjected to Western blotting as described above.

\section{Caspase activity assay}

Briefly, SCC4 cells $\left(1 \times 10^{6}\right)$ were treated with GS for 0 , $6,12,24$ and $36 \mathrm{~h}$ at $37^{\circ} \mathrm{C}$. The caspase enzyme activity in the cell lysates (treated and control) was measured by direct assay using synthetic fluorogenic substrate (AcDEVD-AFC, substrate for caspase 3 (R\&D Systems) and Ac-LEHD-AFC, substrate for caspase 8 and caspase 9. The amount of fluorogenic 7-amino-4-methyl coumarin (AMC)/7-amino-4-trifluoromethyl coumarin (AFC) moiety released was measured using a spectofluorimeter.

\section{CD95/Fas assay}

Briefly, SCC4 cells $\left(1 \times 10^{6}\right)$ were treated with GS for 0 , $6,12,24$ and $36 \mathrm{~h}$ at $37^{\circ} \mathrm{C}$. Cells were harvested, washed with PBS and incubated with FITC-conjugated antibody against CD95 (Fas) for $1 \mathrm{~h}$ at $4^{\circ} \mathrm{C}$. After incubation, cells were washed, suspended in PBS containing $0.05 \%(\mathrm{w} / \mathrm{v})$ sodium azide and analyzed using BD Canto flow cytometer and data were analyzed using the BD FACS Diva software. The gates were set to exclude dead cells and 10,000 cells were analyzed. Data are displayed as percentage of cells showing CD95 positivity.

\section{Statistical Analysis}

Statistical analysis was carried out using SPSS 10.0 software (Chicago). Statistical significance was determined using the paired, two-tailed Student's t-test. $\mathrm{p} \leq 0.05$ was considered to be significant. Each assay was repeated at least 3 times (unless otherwise specified), to check the validity of the results obtained. The mean values \pm standard deviations (S.D.) are presented in figures.

\section{Results}

\section{GS inhibits cell proliferation and induces cell death}

To determine the cytotoxic effect of GS, head and neck cancer cells (SCC4/HSC2) were treated with varying concentrations $(5-100 \mu \mathrm{M})$ for $24 \mathrm{~h}-72 \mathrm{~h}$. MTT assay revealed dose and time dependent increased cytotoxicity of GS in head and neck cancer cells (SCC4 and HSC2) as shown in Figure 1a and 1b respectively. Treatment of SCC4 cells with GS produced a cytotoxic effect with an inhibitory concentration at $50 \%\left(\mathrm{IC}_{50}\right)$ of $50 \mu \mathrm{M}$ and 75 $\mu \mathrm{M}$ in SCC4 and HSC2 cells respectively. Therefore, 50 $\mu \mathrm{M}$ GS was used for all subsequent experiments in (a) $\mathrm{SCC} 4$

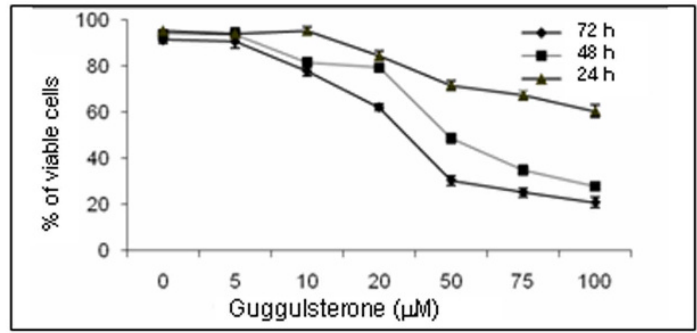

(b) HSC2

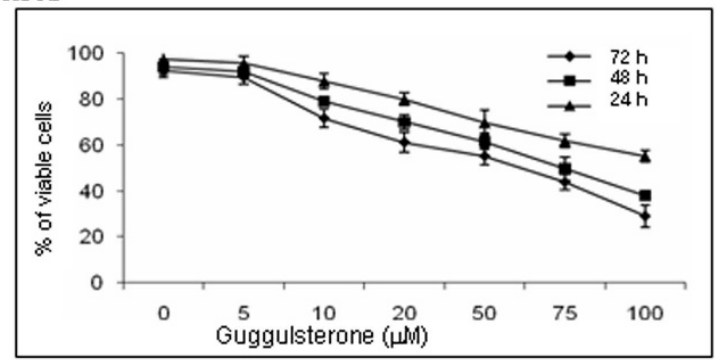

Figure $1 \mathrm{GS}$ reduces cell viability of HNSCC cell lines. Cell viability was determined in SCC4 and HSC2 cells after $24 \mathrm{~h}-72 \mathrm{~h}$ of incubation with 5, 10, 20, 50, 75 and $100 \mu \mathrm{M}$ GS. Viable cell number was assayed by MTT uptake. Graphs show \% of viable (a) SCC4 and (b) HSC2 cells on treatment with GS in a dose- and timedependent manner. Each data point represents the mean \pm standard deviation (S.D.) of 3 independent experiments.

SCC4 cells. Flow cytometry analysis using propidium iodide staining showed significant increase in sub- $G_{0}$ fraction of cell cycle in $24 \mathrm{~h}-48 \mathrm{~h}$ indicating cell death in GS $(50 \mu \mathrm{M})$ - treated SCC4 cells in comparison with untreated control cells (Figure 2A). Interestingly, GStreated SCC4 cells also showed marked differences in $\mathrm{G}_{2} / \mathrm{M}$ fraction of cell cycle in comparison to untreated controls, as revealed by flow cytometry analysis (Figure 2A(iv).

\section{GS treatment induces apoptosis in head and neck cancer cells}

Annexin V assay was carried out to evaluate GS induced apoptosis in head and neck cancer cells. GS treated SCC4 cells showed significant increase in apoptosis $(40 \%)$ as early as in $24 \mathrm{~h}$ (Figure $2 \mathrm{~B}$ ). These results were further confirmed using M30 cyto-death and DNA fragmentation assay. Increased cytoplasmic expression of M30 protein and DNA fragmentation that are characteristics of apoptosis were observed in GS - treated SCC4 cells in $48 \mathrm{~h}$ (Figure $2 \mathrm{C} \& 2 \mathrm{D}$ ). However, no detectable immunostaining was observed by M30-cytodeath assay in the control cells treated with vehicle alone, confirming induction of apoptosis by GS treatment (Figure 2C). 


\section{(A)}

(i) $0 \mathrm{~h}$

(ii) $24 \mathrm{~h}$

(iii) $48 \mathrm{~h}$

(iv)
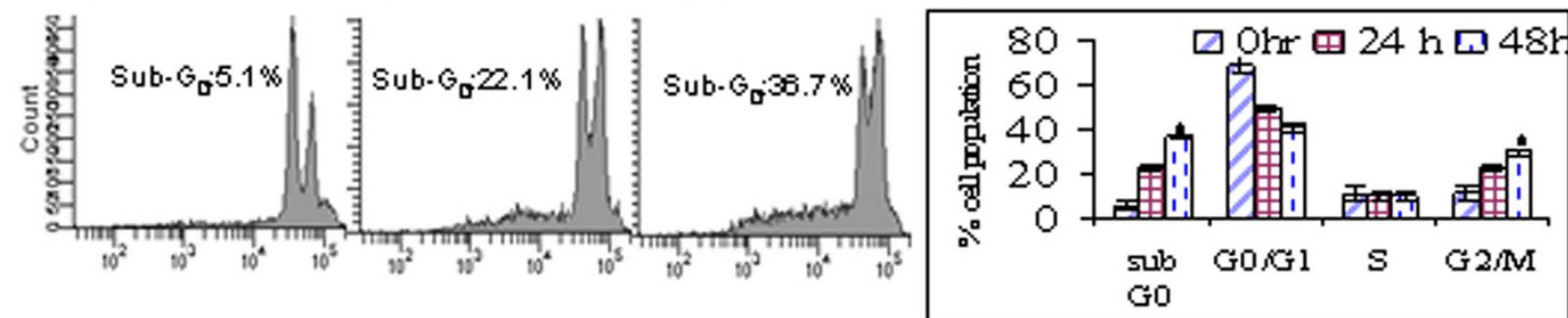

(B)

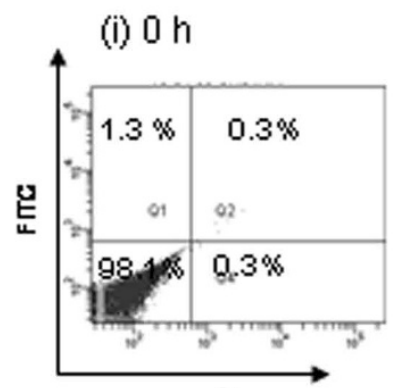

PI (ii) $24 \mathrm{~h}$

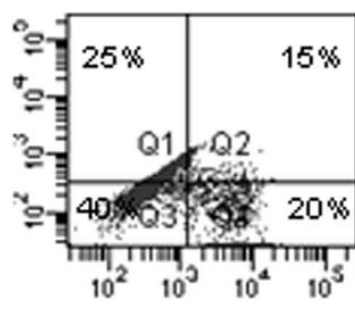

(iii) $48 \mathrm{~h}$

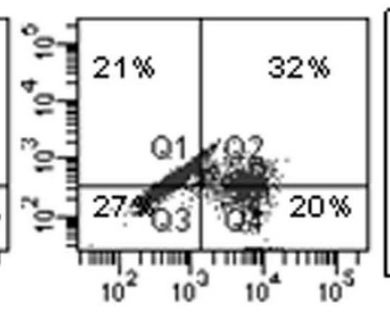

(iv)

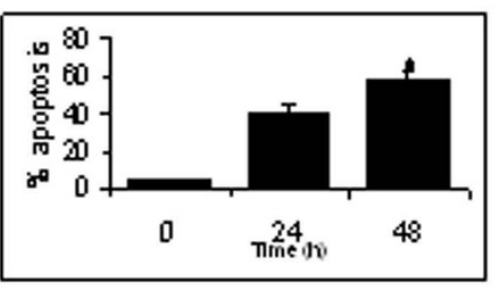

(C)

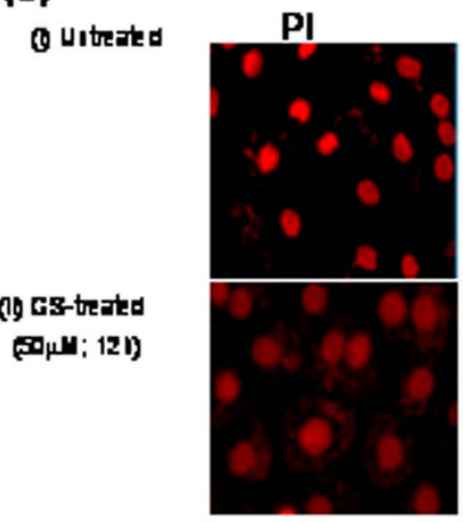

FITC

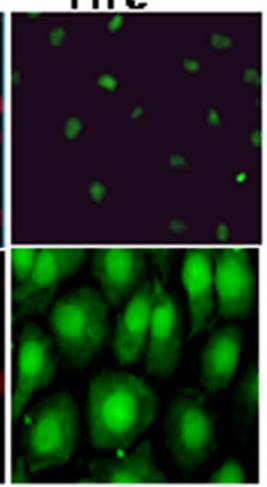

Merged

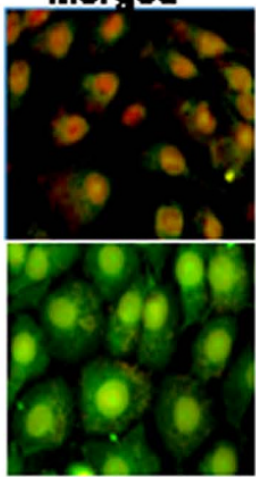

(D)

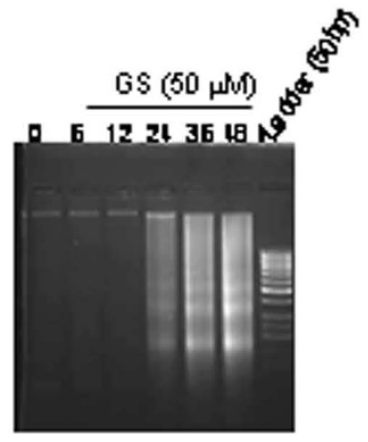

Figure 2 GS induces cell death in HNSCC cells. (A) SCC4 cells treated with $50 \mu \mathrm{M}$ GS for 0 h, 24 h, and 48 h were fixed and stained with propidium iodide and cell cycle analysis was carried out using flow cytometry as described in Materials and Methods. Panel shows

representative DNA histograms of GS-treated SCC4 cells in sub- $G_{0}, G_{0} / G_{1}, S$ - and $G_{2} / M$ phase of cell cycle after (i) 0 h, (ii) 24 h; (iii) 48 h; (iv) histograms showing mean \% of cell population in each phase of cell cycle (* $p<0.05$ ). (B) Annexin $\vee$ assay. The panel shows \% apoptotic cells on treatment with GS (50 $\mathrm{MM}$ ) for (i) $0 \mathrm{~h}$, (ii) $24 \mathrm{~h}$ and (iii) $48 \mathrm{~h}$ and (iv) histogram showing mean \% of apoptotic cells (mean \pm S.D., * $\mathrm{p}<0.005$ ). (C) Immunofluorescence analysis revealing M30 protein expression in SCC4 cells (i) untreated control cells; (ii) GS (50 $\mu$ M) treatment for 12 h (original magnification $\times 400$ ). (D) SCC4 cells were treated with GS $(50 \mu \mathrm{M})$ for $6 \mathrm{~h}-48 \mathrm{~h}$ followed by DNA extraction as described in materials and methods. Panel represents an agarose gel electrophoretogram showing DNA ladder confirming apoptosis. 
Effect of GS on cell cycle regulatory and anti-apoptotic proteins

Treatment with GS $(50 \mu \mathrm{M})$ decreased expression of cell cycle regulatory protein-cyclin D1, while it induced expression of cyclin-dependent kinase inhibitor p21 $1^{\mathrm{WAF} 1 / \mathrm{CIP} 1}$ and $\mathrm{p} 27$ in SCC4 cells in a time dependent manner (Figure 3A(i-iii). Interestingly, GS treatment also induced a significant shift in the $\mathrm{Bax} / \mathrm{Bcl} 2$ ratio within $36 \mathrm{~h}$ of GS treatment in SCC4 cells (Figure 3A(iv-v, xii), while it did not show marked effect on expression of Bak at the indicated time points (Figure 3A(vii), suggesting GS-induced apoptosis in head and neck cancer cells involves the intrinsic mitochondrial pathway. Treatment with GS $(50 \mu \mathrm{M})$ suppressed the expression of antiapoptotic proteins xIAP, Mcl1, c-myc and survivin in SCC4 cells (Figure 3A(viii-xi).

Cytochrome c release from mitochondria is the most important step in the apoptosis cascade involving intrinsic mitochondrial pathway. As shown in Figure 3B, we observed a significant increase in expression of cytochrome c protein in cytosolic fractions of SCC4 cells on treatment with GS in a time dependent manner.

\section{GS induces dissociation of Bad from 14-3-3 zeta to activate intrinsic mitochondrial pathway}

The pro-apoptotic function of Bad requires its localization on outer mitochondrial membrane to release Bax from $\mathrm{Bcl} 2 / \mathrm{Bcl}-\mathrm{xl}$, forming ion pores, thereby increasing membrane permeability releasing cytochrome $\mathrm{c}$ into cytoplasm. However, Bad is sequestered in cytoplasm by 14-3-3 zeta in proliferating cancer cells inhibiting its pro-apoptotic functions. Our results showed a time dependent decrease in expression of phosphorylated-Bad (pBad, Ser-136), while no significant change in expression of total Bad was observed on GS treatment in SCC4 cells (Figure 4A). Using co-immunoprecipitation (co-IP) assays, we showed that decrease in phosphorylation of Bad results in its dissociation from 14-3-3 zeta in the cytosol, on treatment with GS $(50 \mu \mathrm{M})$ as shown in Figure 4B. The dephosphorylated Bad accumulates on

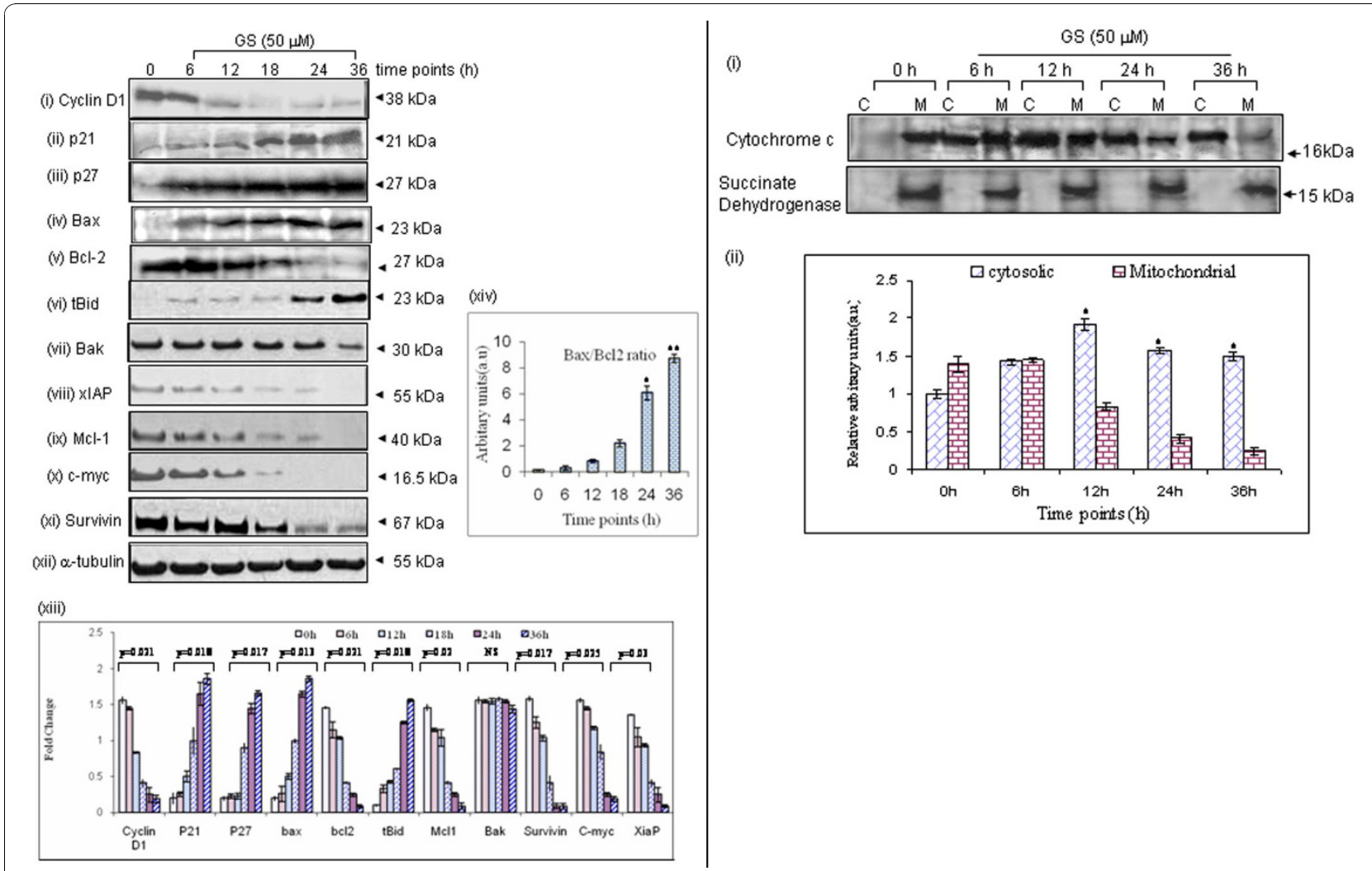

Figure 3 (A) GS modulates cell cycle regulatory and anti-apoptotic proteins. SCC4 cells were incubated for different time points ( $0 \mathrm{~h}$ 36 h) with of GS $(50 \mu \mathrm{M})$ and whole-cell extracts were prepared. Panel shows western blot analysis of (i) cyclin D1, (ii) p27, (iii) p21, (iv) Bax, (v) Bcl2, (vi) Bak, (vii) tBid, (viii) XIAP, (ix) Mcl1, (x) c-myc and (xi) survivin (xii) $\alpha$-tubulin served as a loading control, (xiii) histograms showing fold change (mean \pm S.D.) of protein expression, (xiv) histograms showing increased Bax/Bcl2 ratio (mean \pm S.D.) in SCC4 cells $\left({ }^{* * *} p<0.005\right)(B)$ Panel shows increased expression of cytochrome $\mathrm{c}$ in cytosolic fractions of GS-treated SCC4 cells in a time dependent manner $(0 \mathrm{~h}-36 \mathrm{~h})$. Absence of succinate dehydrogenase (mitochondrial protein) expression in cytosolic fractions (C) confirmed the purity of cytosolic (C) and mitochondrial $(M)$ sub-cellular fractions $\left({ }^{*} p<0.05\right)$. 
(A)

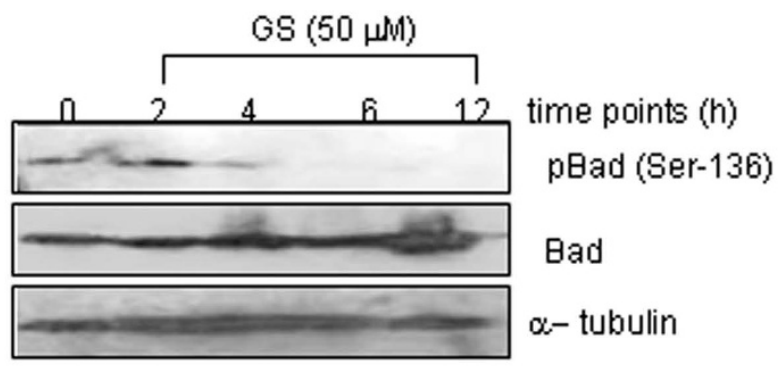

(B)

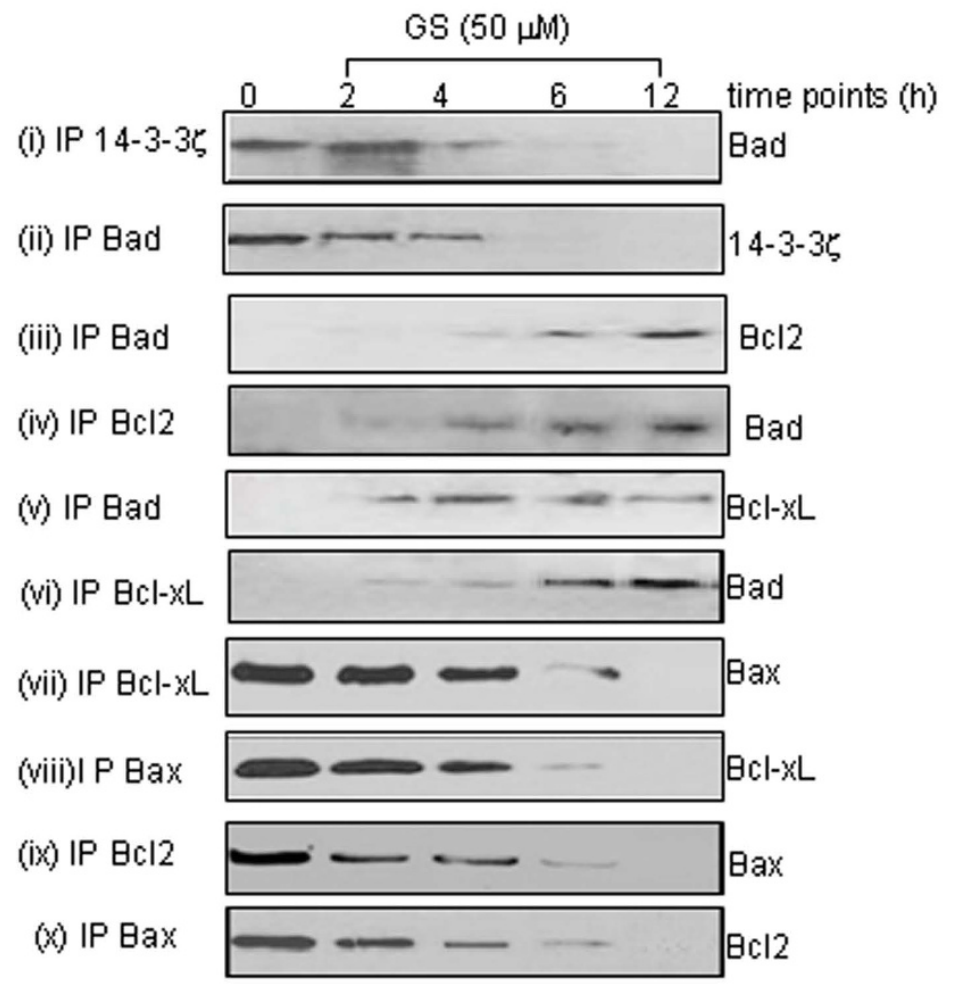

(C)

$$
\begin{aligned}
& \begin{array}{llllll}
0 & 2 & 4 & 6 & 12 & \text { time points (h) }
\end{array} \\
& ++++\quad+\text { OA }(50 \mathrm{nM}) \\
& +\quad+\quad+\quad+\quad \mathrm{GS}(50 \mu \mathrm{M})
\end{aligned}
$$

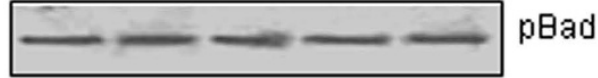

IP 14-3-3ל

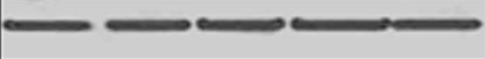

Bad

Figure 4 (A) GS induces dephosphorylation of pBAD. Whole cell lysates obtained from GS $(50 \mu \mathrm{M})$ treated SCC4 cells were subjected to western blotting using specific antibodies for pBad, total Bad and $\alpha$-tubulin. Panel shows the dephosphorylation of Bad in time-dependent manner $(0 h-12 h$ ) while no difference was observed in the expression of total Bad protein in GS-treated SCC4 cells. $\alpha$-tubulin served as

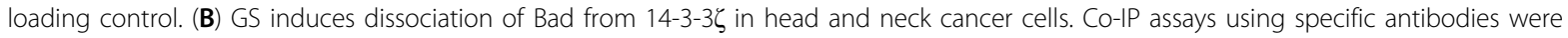
carried out and analyzed by western blotting as described in Materials and Methods. Treatment with GS induced dissociation of Bad from 14-3$3 \zeta$ as shown in panel (i) and (ii); association of Bad with Bcl2 as shown in panel (iii) and (iv); association of Bad with Bcl-xL (v) and (vi); and dissociation of pro-apoptotic protein Bax from BCl-xL (vii and viii) as well as BCl2 (ix and x) (C) Okadaic acid (OA) inhibits GS-induced dephosphorylation of Bad. Panel shows inhibition of dephosphorylation of Bad (Ser-136) and its dissociation from 14-3-3 in a time-dependent manner as determined using co-IP assays followed by western blotting. 
outer mitochondrial membrane forming heterodimers with either $\mathrm{Bcl} 2$ or $\mathrm{Bcl}-\mathrm{xl}$ releasing Bax from inhibitory action of these anti-apoptotic proteins as revealed by co-IP assays using specific antibodies (Figure 4B). These results were further confirmed by reverse co-IP assays followed by western blotting.

The dephosphorylation of Bad on Ser-136 has been reported by protein phosphatases $2 \mathrm{~A}$ (PP2A) in response to various apoptotic stimulus [39]. Therefore, we evaluated dephosphorylation of Bad and its dissociation from 14-3-3 zeta on GS treatment $(50 \mu \mathrm{M})$ in presence of serine/threonine phosphatase inhibitor, okadaic acid (OA). Our results clearly showed no change in dephosphorylation of $\mathrm{pBad}$ on treatment with GS in presence of okadaic acid (OA) (Figure 4C). Further, co-IP assays showed inhibition of dissociation of pBad from 14-3-3 zeta on GS-treatment in presence of OA, thereby inhibiting apoptosis (Figure 4C). These results suggest that GS recruits a phosphatase to release pro-apoptotic protein, Bad from 14-3-3 zeta activating the intrinsic mitochondrial pathway of apoptosis.

\section{Caspase assay}

Caspase 9 and caspase 3 assays were carried out using fluorogenic substrates for quantitative analysis in GS-treated and untreated control SCC4 cells. Fluorimetric analysis revealed increased caspase 9 and caspase 3 activities in a time dependent manner with maximum activity observed at $36 \mathrm{~h}$ of GS treatment (Figure 5A). These results were further verified by presence of cleaved caspase 9 and caspase 3 using western blotting (Figure 5B). GS treatment resulted in cleavage of PARP starting from as early as 18 hrs into respective fragments of $116 \mathrm{kDa}$ and $85 \mathrm{kDa}$ with increased cleavage of PARP by $36 \mathrm{~h}$ (Figure 5B). Taken together, our results demonstrated GS induced apoptosis by activation of the mitochondrial pathway.

\section{Evaluation of extrinsic pathway/death receptor pathway in GS-induced apoptosis}

In addition to induction of mitochondrial pathway for apoptosis, we also evaluated expression of Fas/CD95, truncated Bid (tBid), caspase 8 and its activity. Using flow cytometric analysis, we observed significant increase in Fas/CD95 expression (29.5\%, p = 0.04) in SCC4 cells after 36 hrs with GS (Figure $5 \mathrm{C}$ ). Western blot analysis showed increased expression of tBid (Figure 3A(vi) and cleaved caspase 8 (Figure $5 \mathrm{~B}$ ). These results were further supported by increased caspase 8 activity in GS treated SCC4 cells (Figure 5A), suggesting involvement of extrinsic pathways also in GS induced apoptosis.

\section{Discussion}

Abrogation of apoptosis is important for survival and proliferation of cancer cells. Thus, targeting apoptosis is considered as an effective therapeutic strategy for treatment of cancer $[37,38]$. The $\mathrm{Bcl} 2$ family of proteins, including pro-survival members (Bcl2, Bcl-xL and Mcl1) and pro-apoptotic members (Bax, Bak and Bid) play key role in integrating apoptotic signals [39]. In addition, 14-3-3 proteins play an important role in regulating the balance between survival and apoptotic signaling in multiple ways in cancer cells. Kinases with pro-survival functions, such as AKT, Rsk and PIM, are responsible for generating the 14-3-3 docking sites on target proteins $[25,30]$. The binding of 14-3-3 frequently promotes re-localization of these pro-apoptotic proteins (Bad, Bax, FOXO and Ask1) away from their site of action [25,30-35]. The Bad-14-3-3 interaction causes Bad to be retained in the cytoplasm, thus, preventing Bad from dimerizing with $\mathrm{Bcl} 2 / \mathrm{xL}$ at the mitochondria and mediating the release of $\mathrm{Bax}$ from $\mathrm{Bcl} 2 / \mathrm{xL}$-mediated inhibition [40]. Recently, we reported 14-3-3 zeta overexpression is associated with development, progression, poor prognosis and chemo-resistance in head and neck cancer cells and tissues [26-29]. These findings led us to propose the natural or chemical inhibitors targeting 14-3-3 zeta may serve as potential therapeutic agents for head and neck cancer.

GS is known anti-proliferative agent for inducing apoptosis in prostate, lung, colon and head and neck carcinomas, but the complete mechanism responsible for induction of apoptosis is unclear. In this study, using in vitro models of head and neck cancer, we showed 143-3 zeta as a key player regulating apoptosis in GS treated SCC4 cells. Our co-immunoprecipitation assays demonstrated that in proliferating, untreated control SCC4 cells, pBad (Ser 136) is sequestered in cytoplasm by 14-3-3 zeta, thereby abrogating apoptosis and promoting survival and proliferation. However, treatment with GS revealed dissociation of Bad from 14-3-3 zeta, leading to its accumulation on outer mitochondrial membrane in SCC4 cells. Here, Bad associates with $\mathrm{Bcl} 2 / \mathrm{xL}$, thereby, releasing Bax to form mitochondrial permeability transition pores in GS-treated SCC4 cells. Dissociation of Bad from 14-3-3 zeta and its association with $\mathrm{Bcl} 2 / \mathrm{xL}$, was verified by reverse immunoprecipitation assays. Further, we showed dissociation of Bad from 14-3-3 zeta was a result of dephosphorylation of pBad (Ser 136), a crucial step in decision making for induction of apoptosis. Interestingly, GS treatment activated PP2A phosphatases resulting in cytoplasmic accumulation of dephosphorylated Bad in SCC4 cells. In addition, changes in the $\mathrm{Bax} / \mathrm{Bcl} 2$ ratio also affect mitochondrial membrane potential in cells $[39,40]$. Our results of western blotting showed increased $\mathrm{Bax} / \mathrm{Bcl} 2$ ratio, altering the mitochondrial membrane potential in GS treated SCC4 cells. This results in leakage of cytochrome c from mitochondria into cytoplasm initiating 


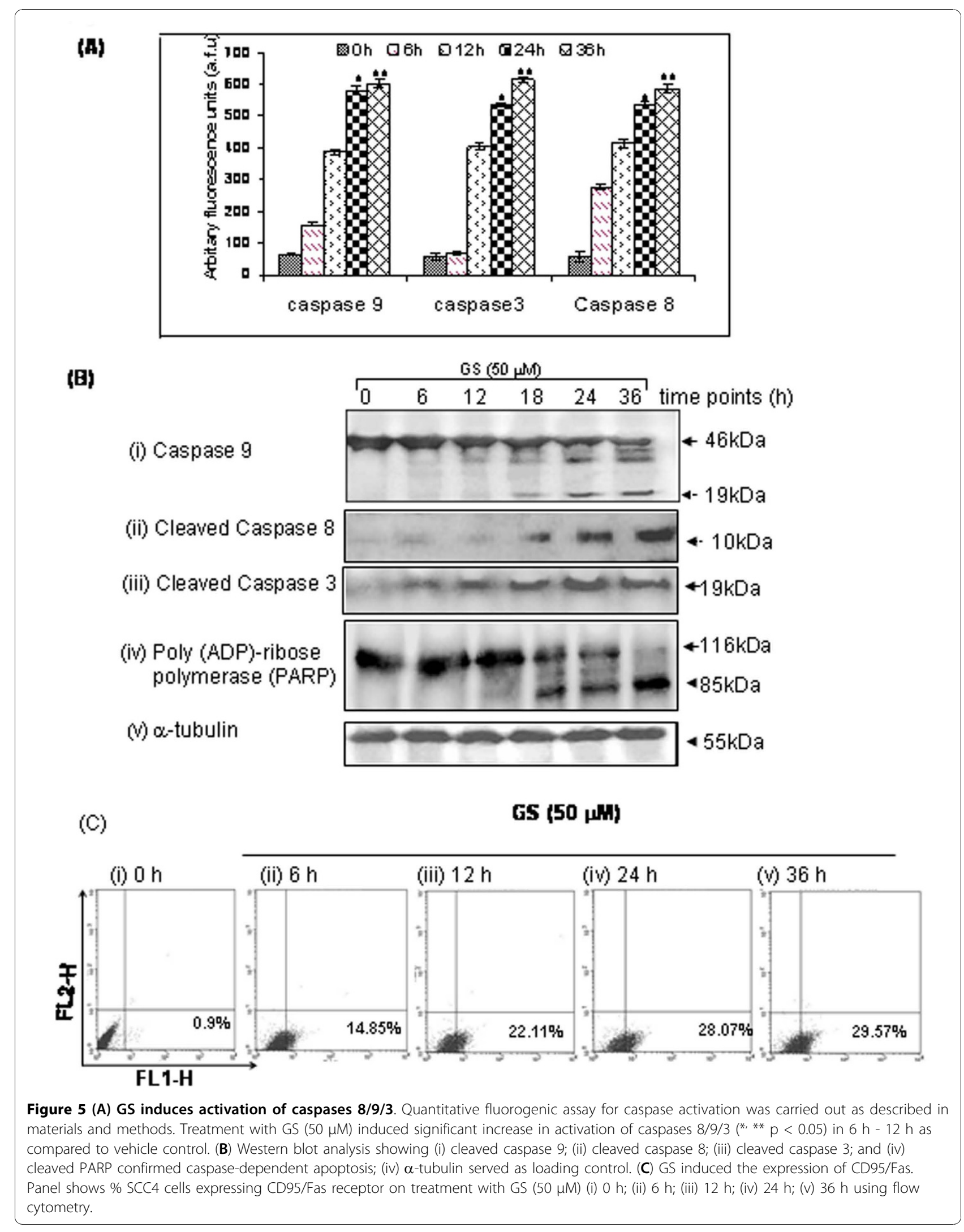




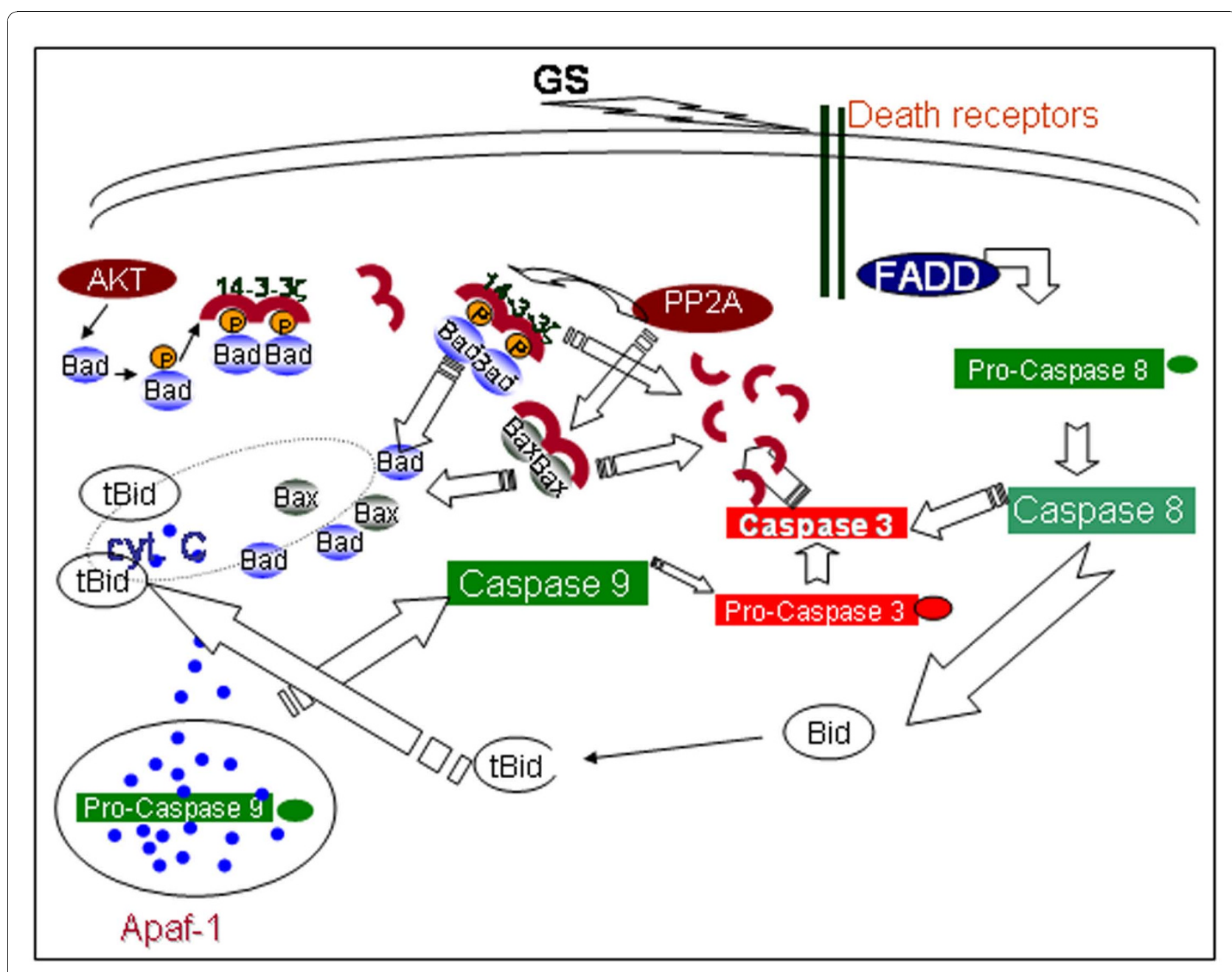

Figure 6 The proposed model of GS-mediated apoptosis in HNSCC cells. Our results demonstrated GS targets 14-3-3 zeta to initiate apoptosis through the intrinsic mitochondrial pathway by releasing Bad from its inhibitory action. Activation of PP2A inhibited association of Bad with 14-3-3 zeta resulting in its accumulation on outer mitochondrial membrane, altering its membrane potential. This releases cytochrome c, activating the downstream caspases - caspase 9 and caspase 3. In addition, treatment with GS induces expression of CD95/Fas receptors leading to caspase 8 activation in head and neck cancer cells.

apoptosis on treatment with GS. Another noteworthy observation in our study was significant decrease in expression of anti-apoptotic proteins, Bcl2, xIAP, Mcl1, survivin, cyclin D1 and c-myc on treatment with GS in comparison with no treatment controls, thus committing cells to apoptosis. These events were followed by activation of caspase 9 and caspase 3 resulting in cleavage of poly (ADP-ribose) polymerase (PARP) in GS treated SCC4 cells. Taken together, these observations suggested 14-3-3 zeta plays a key role in GS-induced apoptosis in head and neck cancer cells as shown in Figure 6.

Similar to our results, GS treatment has been shown to alter mitochondrial membrane potential releasing cytochrome c and initiating apoptosis leukemia, prostate and colon cancer [15,16,18]. GS also mediates its effects through downregulation of Akt pathway which promotes survival and proliferation, but activates JNK pathway inducing apoptosis [13]. In addition, our results also showed increase in expression of CD95/Fas upon GS treatment, in a time dependent manner. This increase in expression of death receptor CD95 coincides with the activation of caspase-8. GS-treatment increased expression of truncated Bid (tBid) in SCC4 cells, in a time dependent manner. Bid is a pro-apoptotic BH3only member of the Bcl-2 family and an important component of Fas-induced apoptosis [41-43]. Bid is cleaved by active caspase- 8 enhancing cytochrome c release from mitochondria into the cytosol. Thus, our findings suggest involvement of both 14-3-3 zeta dependent 
intrinsic and extrinsic pathway in GS induced apoptosis (Figure 6).

\section{Conclusion}

In conclusion, we demonstrated guggulsterone as an effective cytotoxic agent inducing apoptosis in head and neck cancer cells, which are generally chemoresistant. Further, we showed GS targets 14-3-3 zeta to initiate apoptosis through intrinsic mitochondrial pathway by releasing Bad from its inhibitory action. Taken together, our results provide a biologic rationale for designing further studies investigating the clinical utility of GS as a potential complementary therapeutic/chemopreventive agent for head and neck cancer management.

\section{Additional material}

Additional file 1: Supplementary Table S1. Details of the antibodies used in this study.

\section{List of Abbreviations}

HNSCC: Head and neck squamous cell carcinoma; MTT: 3-(4, 5dimethylthiazol-2-yl)-2, 5-diphenyltetrazoliumbromide; PI: Propidium iodide; DMSO: Dimethylsulphoxide; FITC: Fluorescein isothiocyanate; AMC: 7-Amino4-methyl coumarin; AFC: 7-Amino-4-trifluoromethyl coumarin.

\section{Acknowledgements}

MM is recipient of Senior Research Fellowship of Council of Scientific and Industrial Research (CSIR), New Delhi, India. AM is recipient of MITACS Accelerate Fellowship, Ontario, Canada. RR gratefully acknowledges support from the Joseph and Mildred Sonshine Centre for Head and Neck Diseases, Alex and Simona Shnaider Laboratory of Molecular Oncology, Temmy Latner/Dynacare, and the Department of Otolaryngology-Head and Neck Surgery, Mount Sinai Hospital, University of Toronto. KWMS acknowledges funding from the Ontario Institute for Cancer Research (OICR), and infrastructural support from the Ontario Research and Development Challenge Fund and AB SCIEX.

\section{Author details}

1Department of Biochemistry, All India Institute of Medical Sciences, New Delhi-110029, India. ${ }^{2}$ Department of Chemistry and Centre for Research In Mass Spectrometry, York University, 4700 Keele Street, Toronto, Ontario, Canada M3J 1P3. ${ }^{3}$ Department of Chemistry and Centre for Research In Mass Spectrometry, York University, 4700 Keele Street, Toronto, Ontario, Canada M3J 1P3. ${ }^{4}$ Joseph and Mildred Sonshine Family Centre for Head and Neck Diseases and Department of Otolaryngology - Head and Neck Surgery, Mount Sinai Hospital, 600 University Avenue, Toronto, Ontario, Canada M5G 1X5. ${ }^{5}$ Alex and Simona Shnaider Laboratory of Molecular Oncology, Mount Sinai Hospital, Toronto, Ontario, Canada, M5G 1X5. ${ }^{6}$ Department of Pathology and Laboratory Medicine, Mount Sinai Hospital, Toronto, Ontario, Canada, M5G 1X5. ${ }^{7}$ Department of Otolaryngology-Head and Neck Surgery, University of Toronto, Toronto, Ontario, Canada M5G 2 N2.

\section{Authors' contributions}

MM carried out the experiments and contributed in preparing this manuscript. AM analyzed the experiments and contributed in preparing this manuscript. SSC and KWM Siu provided the financial support and edited the manuscript. RR conceived the idea and planned the experiments and contributed in preparing this manuscript. All authors read and approved the final manuscript.

\section{Competing interests}

The authors declare that they have no competing interests.
Received: 1 August 2010 Accepted: 30 November 2010

Published: 30 November 2010

\section{References}

1. Jemal A, Siegel R, Ward E, Hao Y, Xu J, Thun MJ: Cancer statistics. CA Cancer 2009. J Clin 2009, 59:225-249.

2. Bettendorf O, Piffko J, Bankfalvi A: Prognostic and predictive factors in oral squamous cell cancer: important tools for planning individual therapy. Oral Oncol 2004, 40:110-119.

3. Parkin DM, Bray F, Ferlay J, Pisani P: Global cancer statistics, 2002. CA Cancer J Clin 2005, 55:74-108.

4. Argiris A, Karamouzis MV, Raben D, Ferris RL: Head and neck cancer. Lancet 2008, 371:1695-1709.

5. Scully C, Bagan JV, Hopper C, Epstein JB: Oral cancer: current and future diagnostic techniques. Am J Dent 2008, 21:199-209.

6. Slaughter DP, Southwick HW, Smejkal W: Field cancerization in oral stratified Squamous epithelium; clinical implications of multicentric origin. Cancer 1953, 6:963-968.

7. Matta A, Ralhan R: Overview of current and future biologically based targeted therapies in head and neck squamous cell carcinoma. Head Neck Oncol 2009, 1:6

8. Bernier J, Bentzen SM, Vermorken JB: Molecular therapy in head and neck oncology. Nat Rev Clin Oncol 2009, 6:266-277.

9. Gold KA, Lee HY, Kim ES: Targeted therapies in squamous cell carcinoma of the head and neck. Cancer 2009, 115:922-935.

10. Shishodia S, Harikumar KB, Dass S, Ramawat KG, Aggarwal BB: The guggul for chronic diseases: ancient medicine, modern targets. Anticancer Res 2008, 28:3647-3664.

11. Sharma B, Salunke R, Srivastava S, Majumder C, Roy P: Effects of guggulsterone isolated from Commiphora mukul in high fat diet induced diabetic rats. Food Chem Toxicol 2009, 47:2631-2639.

12. Kapoor S: Guggulsterone: a potent farnesoid X receptor antagonist and its rapidly evolving role as a systemic anticarcinogenic agent. Hepatology 2008, 48:2090-2091.

13. Shishodia S, Sethi G, Ahn KS, Aggarwal BB: Guggulsterone inhibits tumor cell proliferation, induces S-phase arrest, and promotes apoptosis through activation of c-Jun N-terminal kinase, suppression of Akt pathway, and downregulation of antiapoptotic gene products. Biochem Pharmacol 2007, 74:118-130.

14. Xiao D, Singh SV: z-Guggulsterone, a constituent of Ayurvedic medicinal plant Commiphora mukul, inhibits angiogenesis in vitro and in vivo. Mol Cancer Ther 2008, 7:171-180.

15. Samudio I, Konopleva M, Safe S, McQueen T, Andreeff M: Guggulsterones induce apoptosis and differentiation in acute myeloid leukemia: identification of isomer-specific antileukemic activities of the pregnadienedione structure. Mol Cancer Ther 2005, 4:1982-92.

16. Singh SV, Zeng Y, Xiao D, Vogel VG, Nelson JB, Dhir R, Tripathi YB: CaspaseDependent apoptosis induction by guggulsterone, a constituent of Ayurvedic medicinal plant Commiphora mukul, in PC-3 human prostate cancer cells is mediated by Bax and Bak. Mol Cancer Ther 2005, 4:1747-1754.

17. Silva J, Dasgupta S, Wang G, Krishnamurthy K, Ritter E, Bieberich E: Lipids isolated from bone induce the migration of human breast cancer cells. $J$ Lipid Res 2006, 47:724-33.

18. An MJ, Cheon JH, Kim SW, Kim ES, Kim TI, Kim WH: Guggulsterone induces apoptosis in colon cancer cells and inhibits tumor growth in murine colorectal cancer xenografts. Cancer Lett 2009, 279:93-100.

19. Lv N, Song MY, Kim EK, Park JW, Kwon KB, Park BH: Guggulsterone, a plant sterol, inhibits NF-kappa B activation and protects pancreatic beta cells from cytokine toxicity. Mol Cell Endocrinol 2008, 289:49-59.

20. Singh SV, Choi S, Zeng Y, Hahm ER, Xiao D: Guggulsterone-induced apoptosis in human prostate cancer cells is caused by reactive oxygen intermediate dependent activation of c-Jun NH2-terminal kinase. Cancer Res 2007, 67:7439-7449.

21. Shishodia S, Aggarwal BB: Guggulsterone inhibits NF-kappaB and IkappaBalpha kinase activation, suppresses expression of anti-apoptotic gene products, and enhances apoptosis. J Biol Chem 2004, 279:47148-47158.

22. Kim ES, Hong SY, Lee HK, Kim SW, An MJ, Kim TI, Lee KR, Kim WH, Cheon JH: Guggulsterone inhibits angiogenesis by blocking STAT3 and VEGF expression in colon cancer cells. Oncol Rep 2008, 20:1321-1327. 
23. Leeman-Neill RJ, Wheeler SE, Singh SV, Thomas SM, Seethala RR, Neill DB, Panahandeh MC, Hahm ER, Joyce SC, Sen M, Cai Q, Freilino ML, Li C, Johnson DE, Grandis JR: Guggulsterone enhances head and neck cancer therapies via inhibition of signal transducer and activator of transcription-3. Carcinogenesis 2009, 30:1848-1856.

24. Ahn KS, Sethi G, Sung B, Goel A, Ralhan R, Aggarwal BB: Guggulsterone, a farnesoid $X$ receptor antagonist, inhibits constitutive and inducible STAT3 activation through induction of a protein tyrosine phosphatase SHP-1. Cancer Res 2008, 68:4406-4415.

25. Morrison DK: The 14-3-3 proteins: integrators of diverse signaling cues that impact cell fate and cancer development. Trends Cell Biol 2009, 19:16-23.

26. Ralhan R, Desouza LV, Matta A, Chandra Tripathi S, Ghanny S, Datta Gupta S, Bahadur S, Siu KW: Discovery and verification of head-and-neck cancer biomarkers by differential protein expression analysis using iTRAQ labeling, multidimensional liquid chromatography, and tandem mass spectrometry. Mol Cell Proteomics 2008, 7:1162-1173.

27. Ralhan R, Desouza LV, Matta A, Ghanny S, Dattagupta S, Thakar A Chauhan SS, Siu KW: iTRAQ-multidimensional liquid chromatography and tandem mass spectrometry-based identification of potential biomarkers of oral epithelial dysplasia and novel networks between inflammation and premalignancy. J Proteome Res 2009, 8:300-309.

28. Matta A, DeSouza LV, Shukla NK, Gupta SD, Ralhan R, Siu KW: Prognostic significance of head-and-neck cancer biomarkers previously discovered and identified using iTRAQ-labeling and multidimensional liquid chromatography tandem mass spectrometry. J Proteome Res 2008, 7:2078-2087

29. Matta A, Tripathi SC, DeSouza LV, Grigull J, Kaur J, Chauhan SS, Srivastava A, Thakar A, Shukla NK, Duggal R, DattaGupta S, Ralhan R, Michael Siu KW: Heterogeneous ribonucleoprotein $\mathrm{K}$ is a marker of oral leukoplakia and correlates with poor prognosis of squamous cell carcinoma. Int J Cancer 2009, 125:1398-1406.

30. Porter GW, Khuri FR, Fu H: Dynamic 14-3-3/client protein interactions integrate survival and apoptotic pathways. Semin Cancer Biol 2006, 16:193-202.

31. Hermeking H: The 14-3-3 cancer connection. Nat Rev Cancer 2003, 3:931-943.

32. Dong S, Kang S, Gu TL, Kardar S, Fu H, Lonial S, Khoury HJ, Khuri F, Chen J: 14-3-3 Integrates prosurvival signals mediated by the AKT and MAPK pathways in ZNF198-FGFR1-transformed hematopoietic cells. Blood 2007, 110:360-369.

33. Zhou J, Shao Z, Kerkela R, Ichijo H, Muslin AJ, Pombo C, Force T: Serine 58 of 14-3-3 zeta is a molecular switch regulating ASK1 and oxidant stressinduced cell death. Mol Cell Biol 2009, 29:4167-4176.

34. Lee JA, Park JE, Lee DH, Park SG, Myung PK, Park BC, Cho S: G1 to S phase transition protein 1 induces apoptosis signal-regulating kinase 1 activation by dissociating 14-3-3 from ASK1. Oncogene 2008, 27:1297-1305

35. Heyninck K, Van Huffel S, Kreike M, Beyaert R: Yeast two-hybrid screening for proteins interacting with the anti-apoptotic protein A20. Methods $\mathrm{Mo}$ Biol 2004, 282:223-241.

36. Matta A, DeSouza LV, Ralhan R, Siu KW: Small interfering RNA targeting 14-3-3 3 increases efficacy of chemotherapeutic agents in head and neck cancer cells. Mol Cancer Ther 2010, 9:2676-88.

37. Macha MA, Matta A, Sriram U, Thakkar A, Shukla NK, Datta Gupta S, Ralhan R: Clinical significance of TC21 overexpression in oral cancer. $J$ Oral Pathol Med 2010, 39:477-85.

38. Kuhar M, Sen S, Singh N: Role of mitochondria in quercetin-enhanced chemotherapeutic response in human non-small cell lung carcinoma $\mathrm{H}$ 520 cells. Anticancer Res 2006, 26:1297-1303.

39. Chiang CW, Kanies C, Kim KW, Fang WB, Parkhurst C, Xie M, Henry T, Yang E: Protein phosphatase 2A dephosphorylation of phosphoserine 112 plays the gatekeeper role for BAD-mediated apoptosis. Mol Cell BiOl 2003, 23:6350-6362.

40. Patel MP, Masood A, Patel PS, Chanan-Khan AA: Targeting the BCl-2. Curr Opin Oncol 2009, 21:516-23.

41. Pathania $D$, Millard $M$, Neamati $N$ : Opportunities in discovery and delivery of anticancer drugs targeting mitochondria and cancer cell metabolism. Adv Drug Deliv Rev 2009, 61:1250-75.

42. Chipuk JE, Moldoveanu T, Llambi F, Parsons MJ, Green DR: The BCL-2 family reunion. Mol Cell 2010, 37:299-310
43. Yin XM, Wang K, Gross A, Zhao Y, Zinkel S, Klocke B, Roth KA, Korsmeyer SJ: Bid-deficient mice are resistant to Fas-induced hepatocellular apoptosis. Nature 1999, 400:886-891.

\section{Pre-publication history}

The pre-publication history for this paper can be accessed here: http://www.biomedcentral.com/1471-2407/10/655/prepub

doi:10.1186/1471-2407-10-655

Cite this article as: Macha et al:: 14-3-3 zeta is a molecular target in guggulsterone induced apoptosis in Head and Neck cancer cells. BMC Cancer 2010 10:655.

\section{Submit your next manuscript to BioMed Central and take full advantage of:}

- Convenient online submission

- Thorough peer review

- No space constraints or color figure charges

- Immediate publication on acceptance

- Inclusion in PubMed, CAS, Scopus and Google Scholar

- Research which is freely available for redistribution
C) Biomed Central 